\title{
The hostile takeover of medicine
}

Among the major nations of the world, the United States is the only one that does not have some form of universal medical care - an insurance program that covers everyone regardless of income, employment, or health. President Bill Clinton made health care reform the centerpiece of his first two years in office, and he developed a proposal so diabolical and bureaucratic in design that no one could understand it. It died stillborn - and a good thing, too. But in the long run, the failure of the United States to develop a humane and sensible plan to provide for the health of the nation is leading to disaster - for hospitals, for physicians, research, and most importantly, for patients.

The Clinton plan was based on the concept of 'managed care'. You or your employer pay a fixed premium to a health maintenance organization or managed care plan (euphemisms for insurance companies), and the insurer, in

\section{An ideal patient is a patient who}

\section{is never seen.}

The insurance company receives a premium for the care of every patient enrolled in its system. If you go to the doctor or hospital, the company has to pay. If your care costs more than the negotiated price, the doctor or hospital has to make up the difference. But if you stay home, the company makes money. It keeps your insurance premium and pays nothing out. No wonder managed care is about limiting care. An ideal patient is a patient who is never seen.

The next best patient is one who never needs the services of an expensive medical centre. To be competitive economically with community hospitals, the nation's leading medical centres are feverishly merging, streamlining and trying to create managed care companies of their own, to preclude being owned by someone else.

Health care and academic medicine are national and international resources. My bet is that their salvation will come from patients who, group by group, are becoming "madder than hell" at the limits imposed on them by managed care companies.

One group that has been heard from lately are new mothers, whose managed care insurers demand that they leave the hospital within 24 hours of giving birth, whether or not they or their babies could benefit from an extra day. In several states, legislators are drafting laws that would require insurers to pay for a two-day stay.

Emergency care is another contentious issue. Some managed care plans refuse to pay for emergency care unless the company gives prior approval to go to the emergency room - a contradiction if there ever was one. Other insurers define 'emergency' retrospectively. If you go to an emergency room with chest pains that turn out to be a heart attack, it's an emergency, and covered by insurance. But if your chest pains turn out to be heartburn, the insurer refuses to pay. Again, as legislators respond to the protest of their constituents, laws are being drafted to regulate managed care in emergencies.

All of this is a messy, piecemeal approach, and biomedical research institutions will be hurt in the process. The biomedical research enterprise survived on a system of cost-shifting that is in need of overhaul. But what we have now is simply cost-shifting by another name. Money that used to be 'shifted' from one part of the health care system to another is now being shifted to the bank accounts of managed care companies, whose chief executives make as much as $\$ 15-20$ million a year. This is not progress.
Barbara J. Culliton 